\title{
PROBLEMATIKA PEMILIHAN MATERI MUFRODAT MENURUT PERSPEKTIF RUSYDI AHMAD THU'AIMAH
}

\author{
Kholidun Ashari \\ UIN Sunan Ampel Surabaya \\ Corresponding Author: kholidd95@gmail.com
}

\section{Article History}

Submitted: 18 Jul 2020; Revised: 18 Dec 2020; Accepted: 31 Dec 2020

DOI 10.20414/tsaqafah.v19i2.2370

\begin{abstract}
The aim of this study is therefore to identify the types of problems of teachers in the selection of Arabic mufrodat in Grade VII students of Madrasah Tsanawiyah Fadllillah. The method used in this research, using research and development methods (R\&D) refers to the Thiagarajan $4 \mathrm{D}$ model, which focuses on the definition or definition phase, using the Rusydi Ahmad Thu'aimah mufrodat selection principle, which is divided into seven mufrodat selection principles. This research was carried out at one of the most cumbersome educational institutions in the Waru area, at MTs. Fadllillah J1. Kyai Ali No 57 A Sidoarjo Waru Sidoarjo. The results of this study have led to the discovery of many of the problems faced by teachers in determining good, accurate and effective mufrodats to be taught to students. For example, the appropriateness of the principles for the selection of mufrodat according to the principle of frequency is the choice of mufrodat in accordance with the application of everyday language, but there are also principles that are not appropriate, such as the principle of availability of teachers who do not know the ability of students to understand words.
\end{abstract}

Keywords: mufrodat, Rusydi Ahmad Thu'aimah, mufrodat selection

Abstrak: Penelitian ini bertujuan untuk mengetahui macam-macam problematika guru dalam pemilihan mufrodat bahasa Arab pada siswa kelas VII Madrasah Tsanawiyah Fadllillah. Metode yang digunakan pada penelitian ini, menggunakan metode penelitian dan pengembangan atau (R\&D) mengacu pada model 4D menurut Thiagarajan difokuskan pada tahap define atau pendefisian, dengan menggunakan prinsip pemilihan mufrodat menurut Rusydi Ahmad Thu'aimah yang terbagi menjadi tujuh prinsip pemilihan mufrodat. Pelaksanaan penelitian ini terjadi disalah satu lembaga pendidikan pesantren yang berada di daerah Waru tepatanya di MTs. Fadllillah Jl. Kyai Ali No 57 A Tambak Sumur Waru Sidoarjo. Adapun hasil penelitian ini, mampu mengetahui banyak permasalahan yang dihadapai oleh guru 
dalam menentukkan mufrodat yang baik, tepat dan efektif untuk diajarkan pada para siswa. Seperti, kesesuaian prinsip dalam pemilihan mufrodat pada prinsip frekuensi yaitu dipilihnya mufrodat sesuai dengan penerapan bahasa keseharian, namun terdapat pula prinsip yang tidak sesuai seperti prinsip availability guru kurang mengetahui kemampuan siswa dalam memahami kata.

Kata-kata kunci: mufrodat, Rusydi Ahmad Thu'aimah, pemilihan kosa kata.

\section{A. Pendahuluan}

Bahasa Arab merupakan salah satu bahasa yang diajarkan di sekolah-sekolah Indonesia khususnya dari jenjang Madrasah Ibtidaiyah (MI), Madrasah Tsanawiyah (MTs), dan Madrasah Aliyah (MA). Penguasaan Bahasa Arab meliputi empat aspek keterampilan berbahasa, yaitu istima' (mendengarkan), kalam (berbicara), qiroaah (membaca), dan kitabah (menulis). Dari keempat aspek keterampilan berbahasa tersebut merupakan satu kesatuan yang tidak mungkin dapat dipisahkan dalam mempelajari Bahasa Arab, selain keempat aspek tersebut terdapat dua kemampuan dalam penguasaan berbahasa yang harus diperhatikan siswa yaitu penguasaan mufrodat dan tata bahasa (tarkiibul lughah).

Kata mufrodat menurut Moh Mansyur dalam judul buku yang dia tulis Dalil al-Katib Wa al-Mutarajim, mufrodat merupakan bentuk jama' dari kata mufradah diartikan sebagai lafaz atau kata yang terbagi menjadi dua huruf atau lebih yang mana menunjukkan sebuah makna ${ }^{1}$. Kata ialah sebuah lafaz tunggal yang memiliki makna. ${ }^{2}$ Sedangkan menurut Ali al-Khuli mufrodat ialah satuan bahasa yang berdiri sendiri, terkadang kata tersebut berupa kata dasar atau berupa kata imbuan. Selain itu, sebuah kata memiliki bentuk, makna, dan fungsinya masing-masing. ${ }^{3}$ Dengan demikian, dapat ditarik kesimpulan bahwasanya mufrodat merupakan unsur bahasa terkecil yang dapat bediri sendiri terkadang berbentuk kata dasar atau berbentuk kata imbuan yang memiliki arti, bentuk, serta fungsinya masing-masing sehingga mufrodat merupakan salah satu bagian dasar terpenting dalam mempelajari bahasa Arab.

Sedangkan pengertian tata bahasa, suatu aturan yang diterapkan dalam penggunaan bahasa agar dapat dipahami oleh lawan bicara dengan baik dan benar yang memiliki seperangkat aturan untuk digunakan oleh setiap manusia dalam berbicara atau menulis agar mempengaruhi susunan kata-kata dalam sebuah kalimat dengan menggunakan ilmu shorof dan nahwu. Dengan begitu, tata bahasa tidak dapat dipisahkan dari mufrodat sebagai pelengkap dalam penyusunan kalimat yang sempurna.

1 Moh. Mansyur, Dalil al-Katib Wa al-Mutarajim, (Jakarta: PT. Moyo Segoro Agung, 2002), 135.

2 Hafni Bik Nafis dkk, Qawaid al-Lughat al-Arabiyyah, (Semarang: Maktabah al-Alawiyah, t..t.), 1 2010), 79 .

3 Muhammad Ali al-Khuli, Strategi Pembelajaran Bahasa Arab, (Yogyakarta: Basan Publishing, 
Penguasaan mufradat dan tata bahasa merupakan unsur dasar yang penting untuk digunakan mempelajari bahasa Arab, tanpa penguasaan keduanya seseorang tidak akan mampu berkomunikasi dengan baik, Dalam menguasai dasar bahasa tersebut kurang dapat diperhatikan oleh banyak kalangan siswa karena itu, mereka kesulitan dalam mendengarkan, mengucapkan, dan menulis bahasa Arab dengan tepat.

Problematika pemilihan mufrodat yang dialami oleh kebanyakan guru adalah tidak memperhatikan aspek-aspek dasar yang telah ditentukkan oleh para ahli bahasa seperti Rusdi Ahmad Thu'aimah pada karyanya ia menjelaskan bahwa terdapat tujuh perinsip dasar dalam pemilihan materi mufrodat diantaranya prioritas penggunaan mufrodat, standar bahasa menurut pemilik bahasa, bahasa yang mudah digunakan siswa, familiar di kalangan siswa, ketercakupan, kepentingan, dan asli dari bahasa Arab.

Dalam pembelajaran mufrodat bahasa Arab di MTs. Fadllillah untuk kelas VII diadakan setiap hari Sabtu sampai Rabu pada pukul 06.30 WIB setelah para siswa melaksanakan sholat dluhah berjamaah. Metode yang digunakan dalam pembelajaran mufrodat bahasa Arab adalah metode al ilqoiyah dan at tahawuriyah. Dalam pembelajaran ini guru lebih aktif memberikan tiga mufrodat baru dan menjelaskan kepada siswa dengan menggunakan contoh kalimat. Dengan demikian penelitian ini bertujuan untuk menemukan problematika guru dalam pemilihan materi mufrodat bahasa Arab yang diajarkan pada siswa kelas VII Madrasah Tsanawiyah Fadllillah.

\section{B. Landasan Teori}

\section{Pengertian dan Tujuan Pembelajaran mufrodat}

Sebagai siswa dalam mempelajari mufrodat bukanlah sebuah masalah agar mereka memiliki beberapa kriteria sebagai berikut: dapat mempelajari sebuah kata, hanya sekedar hafal arti kata tersebut, mengetahui cara pengimbuan kata, atau mencari kata dasarnya dalam sebuah tatanan bahasa yang benar. Bahwasanya, kriteria diatas mampu menjadikan siswa dapat mempelajari mufrodat dengan baik dan menjadikannya dalam sebuah kalimat atau ucapan kepada lawan bicara dan mampu menggunakan kata sesuai dengan kebutuhannya.

Upaya dalam mengevaluasi pembelajaran bahasa Arab sebagai bahasa kedua bagi para siswa dengan memiliki banyak kata yang dihafal menggambarkan meraka pada suatu pekerjaan yang tidak ilmiah akan tetapi menghilangkan waktu belajar dan kesungguhan meraka. Evaluasi pembelajaran yang benar untuk mempelajari mufrodat ialah siswa dapat menggunakan kata yang sudah didapat dengan menghubungkannya dengan berbahasa seperti berbicara menggunakan bahasa Arab, mendengarkan percakapan bahasa Arab, membaca serta memahami teks Arab, dan menulis teks Arab yang sesuai dengan tatanan bahasa yang benar sehingga mereka menguasai mufrodat yang sudah dimiliki. 
Dilain sisi pengertian penguasaan mufrodat bahasa Arab merupakan kemampuan seseorang untuk menggunakan mufrodat yang dimiliki agar dapat berkomunikasi dan mengungkapkan ide atau gagasan dengan lingkungannya baik dengan tulisan maupun lisan yang ditandai dengan berkembangnya kemampuan dasar berbahasa seperti menyimak, menulis, berbicara dan membaca menggunakan bahasa Arab. ${ }^{4}$

Jadi penguasaan mufrodat sangat mempengaruhi keterampilan berbahasa siswa. Pentingnya pembelajaran mufrodat terhadap pengembangan dan peningkatan kemampuan siswa berbahasa menyebabkan pembelajaran mufrodat semakin mendesak untuk dilakukan lebih terarah dan serius karena kegiatan pembelajaran bahasa Arab di lapangan banyak dijumpai siswa yang kesulitan dalam berkomunikasi dengan bahasa Arab terutama dengan penguasaan empat keterampilan berbahasa. ${ }^{5}$

Adapun tujuan pembelajaran mufrodat dalam menguasai bahasa Arab diantaranya adalah Pertama, memperkenalkan kosa kata baru kepada siswa baik melalui pemahaman menyimak atau buku bacaan. Kedua, membiasakan siswa untuk dapat melafalkan kosakata baru dengan baik dan benar agar mereka mahir dalam berbicara dan membaca. Ketiga, memahami arti kosakata yang didapat baik secara leksikal maupun ketika digunakan sesuai dengan konteks kalimat. Keempat, mampu memberi apresiasi dan menfungsikan mufrodat dalam berkomunikasi dengan lisan maupun tulisan secara baik dan benar. ${ }^{6}$

\section{Prinsip pemilihan mufrodat menurut Rusydi Ahmad Thuaimah.}

Ilmuan bahasa yang terkenal dengan nama lengkap Rusydi Ahmad Abdulllah Thu'aimah ialah guru yang ahli dalam bidang kurikulum dan metode pembelajaran bahasa Arab di fakultas Tarbiyah, Universitas Negeri Mansoura Mesir, Ia memperoleh gelar magister dari Universitas 'Ainus Syams fakultas Sastra pada tahun 1971 Masehi. Dan mendapatkan gelar doktor dari pendidikan bahasa Arab untuk bahasa asing di kampus Minnesota Amerika pada tahun 1979 Masehi. $^{7}$

Dalam penguasaan mufrodat terdapat berbagai kata yang harus dimiliki sesuai dengan tingkat kemampuan pelajar bahasa Arab sebagai bahasa kedua atau bahasa yang sedang mereka pelajari, menurut Thu'aimah ia menawarkan dalam tingkat pemula harus memiliki 750/1000 kosa kata, untuk tingat menengah 1000/1500 kosa kata, dan 1500/2000 untuk tingkat lanjutan. ${ }^{8}$

4 Zahrotun Fajriah, "Peningkatan Penguasaan Kosakata Bahasa Arab (Mufrodat) Melalui Penggunaan Media Kartu Kata Bergambar”, Jurnal Pendidikan Usia Dini, Vol. 9, Edisi 1, April 2015.112.

5 Widi Astuti, "Berbagai Strategi Pembelajaran Kosa Kata Bahasa Arab”, Jurnal Komunikasi dan Pendidikan Islam, Vol.5, No.2, Desember 2016.178.

6 Mu’at, "Strategi Pembelajaran Kosakata (Mufrodat) Bahasa Arab, Jurnal Al Ta'dib, Vol.3, No. 1, Juli 2013.84 .

7 Azkia Muharom Albantani, “Mustawiyaat Talum wa Ta’liimil Lughah Al-Arobiyah 'Inda Rusydi Ahmad Thu'aimah”, Arabiyât Jurnal Pendidikan Bahasa Arab dan Kebahasaanaraban, vol. I, No. 1, Juni 2014. 138 .

8 Rusydi Ahmad Thu'aimah, Ta'lim al-Arabiyyah fi Ghair al-Nathiqina biha; Manahijuhu wa Asalibuhu, (Rabath: Isisco, Cet I, 1989), 196. 
Rusydi Ahmad Thu'aimah merupakan konsulat dari berbagai institusi Arab dan asing pada majalah Arab dan pendidikan bahasa Arab, Ia telah menulis banyak karya ilmiah dan buku. Diatara buku yang terkenal adalah: Dalilul Amal fi 'Idadil Mawad at-Ta'limiyah, Ta'limul 'Arabiyah li Ghairin Natiqin biha, al-Marja' fi Ta'limil Lughah alArabiyah.

Dalam salah satu buku Thu'aimah yang berjudul Ta'lim al-'Arabiyyah fi Ghair al-Nathiqina biha; Manahijuhu wa Asalibuhu menjelaskan adanya tujuh prinsip dalam belajar mufrodat, yaitu sebagai berikut: ${ }^{9}$

Pertama, التواتُ (Frequency), maksud dari kata frekuensi ialah penggunaan mufrodat yang sering diterapkan dalam berkomunikasi setiap hari sehingga mufrodat tersebut diprioritaskan untuk diajarkan daripada yang jarang digunakan. Jadi dalam pemilihan mufrodat yang akan diajarkan hendaknya memilih berdasarkan tingkat penggunaannya lebih tinggi agar lebih efektif.

Kedua, التوازّع أو المدى (Range), merupakan mufrodat yang sudah diresmikan menjadi kata nasional negara arab dan sering digunakan oleh orang Arab, menggunakan standard acuan Mu'jam al-Rasyid al-Lughawii li Al-Tifl al-'Arabii yang disusun oleh ISESCO. bukan mufrodat yang tercipta dari negara lain. Jadi dalam pemilihan mufrodat yang hendak diajarkan, harusnya lebih memilih mufrodat yang sudah menjadi standart bahasa di negara Arab agar tidak terjadi kerancuan dalam berkomunikasi.

Ketiga, المتاحية(Availability) atau dalam bahasa Indonesia diartikan ketersediaan. Sebuah kata yang dikuasai oleh individu ketika ia mengutamakan mufrodat yang diketahui daripada tidak diketahui. Sebagaimana contoh lafadz جََََ lebih dikuasai penutur daripada lafadz قَعَدَ. Mufrodat terpilih yang diajarkan kepada murid hendaknya menyesuaikan dengan keadaan sekitar atau bahasa sehari-hari yang lebih mudah diterima oleh siswa. Agar mufrodat tidak terkesan aneh dan susah di telinga mereka.

Keempat الألفة (Familiar), familiar disini adalah kata yang sering didengarkan dan digunakan penutur, sehingga harus mengutamkan pembelajarannya daripada kata yang jarang digunakan, meski memiliki kesamaan makna. Contohya pada lafadz lebih familiar dari pada lafadz قَلَمُ رَصَاص. Dalam pemilihan mufrodat hendaknya gurú memilih mufrodat yang lebih familiar digunakan murid dan memberikan persamaan kata agar siswa tertarik untuk berfikir kreatif dan lebih aktif dalam pembelajaran mufrodat bahasa Arab.

Kelima, الشمول(Coverage) disebutkan juga dengan ketercakupan. maksudnya adalah satu kata yang memiliki pengertian dalam mencakup banyak hal perlu diprioritaskan dari pada kata yang hanya dapat digunakan dalam satu bidang saja.

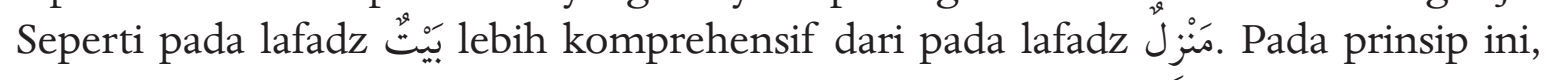

9 Rusydi Ahmad Thu'aimah, Ta'lim al-Arabiyyah fi Ghair al-Nathiqina biha; Manahijuhu wa Asalibuhu, 195-196. 
guru harus memilah mufrodat yang akan disampaikan berdasarkan kata yang lebih umum digunakan oleh siswa agar mudah diterima dan diterapkan dalam berbicara.

Keenam الأهمية (Significance) yang bermakna kepentingan, kata yang perlu dan dianggap penting untuk diketahui harus lebih diutamakan dari pada yang kurang atau tidak sedang dibutuhkan. Maksud dari penjelasan tersebut yaitu dalam memilih mufrodat hendaknya guru memilih sesuai yang dibutuhkan siswanya. Seperti mufrodat untuk kegiatan sehari-hari yaitu makan, minum, mandi dan lain sebagianya.

Dan ketujuh العروبة(Ke-Araban), maksudnya yaitu mufrodat yang dipilih untuk diajarkan adalah kata-kata yang berasal dari negara Arab, bukan mengajarkan mufrodat yang berasal dari kata serapan negara lain. Contohnya pada kata الهاتف dan kata التلفون. Karena lafdz pertama merupakan dari bahasa Arab asli.

\section{Metode Penelitian}

Penelitian ini menggunakan metode penelitian dan pengembangan atau research and development dengan pendekatan diskriptif kualitatif mengacu pada model pengembangan penelitian 4D, Penelitian model ini merupakan salah satu model penelitian dan pengembangan sistem pembelajaran yang merupakan singkatan dari define (pendefisian), design (perancangan), development (pengembangan), and dissemination (penyebarluasan) yang dikembangkan oleh Thiagarajan. ${ }^{10}$

Penelitian pengembangan dapat didefinisikan sebagai kajian sistematik tentang proses perancangan, pengembangan, evaluasi, serta memenuhi kriteria konsistensi internal dan efektivitas penggunaan program atau produk dalam penelitian ini melibatkan cukup banyak partisipan agar menjadi penelitian yang baik. Partisipan tersebut terdiri dari perancang/ pengembang/ evaluator, siswa/ peserta didik, pengajar/ fasilator program, dan peneliti yang menguasai teori, serta pengguna produk. $^{11}$

Adapun penelitian ini difokuskan pada tahap define atau terdiri dari penentuan problematika-problematika pemilihan materi mufrodat, pengembangan pemilihan materi pembelajaran mufrodat dan pengamatan yang akan dituliskan secara deskriptif kualitatif oleh peneliti.

Instrument penelitian yang digunakan pada penelitian ini yaitu peneliti itu sendiri melalui teknik observasi dan wawancara kepada sebagian siswa dan guru. ${ }^{12}$ Teknik pengumpulan data, harus dilakukan dengan benar agar dapat dipertanggungjawabkan serta mampu berbicara banyak untuk menyimpulkan sesuatu yang ada. macammacam teknik pengumpulan data pada penelitian ini yaitu dengan wawancara dan

10 Thiagarajan, Shivasailam, dkk, Instructional Development for Training Teachers of Exceptional Children, (Washinton DC: National Center for Improvement System, 1974), 5.

11 M. Haviz, "Research and Development; Penelitian Di Bidang Kependidikan yang Inovatif, Produktif, dan Bermakna, Jurnal Ta’dib, Vol. 16, No. 1, Juni 2013.29-31.

12 Sugiyono, Metode Penelitian Kuantitatif Kualitatif dan R\&D, (Bandung: Alfabeta, 2014). 222-223 
pengamatan. Adapun jenis data dan sumber data ada enam jenis ${ }^{13}$ yaitu kata-kata, tindakan, sumber tertulis, foto, data statistik dan dokumen-dokumen. pada analisa kali ini peneliti menggunakan data dan sumber data berdasarkan hasil kata-kata wawancara dan pengamatan terhadap buku pedoman yang digunakan guru dalam pengajaran mufrodat.

\section{Pembahasan}

Penelitian ini diadakan di Madrasah Tsanawiyah Fadlillah, daerah Waru tepatnya di Jl. Kyai Ali No 57 A Tambak Sumur Waru Sidoarjo. Sekolah ini menerapkan Format pendidikan yang dipadukan antara dua kurikulum pendidikan yaitu kurikulum Mu'allimin (Gontor) yang disebut dengan Tarbiyatul Mu'alimin Al Islamiyah (TMI) dengan kurikulum Dapertemen Agama (Depag) dari Madrasah Tsanawiyah dan Madrasah Aliyah. Adapun fokus penelitian ini dilaksanakn di kelas VII MTs yang terdiri dari enam kelas setiap kelas berjumlah 29-32 siswa, tiga kelas untuk lakilaki, dua kelas untuk perempuan, dan satu kelas untuk kelas campuran laki-laki dan perempuan.

Pembelajaran bahasa Arab di kelas VII MTs Fadlillah Sidoarjo bertujuan agar siswa mampu berinteraksi menggunakan bahasa asing dengan lancar dan dapat membaca teks bahasa Arab serta memahaminya. Salah satu upaya guru dalam mengajarkan bahasa Arab kepada siswa dengan mengajarkan mufrodat setiap hari kecuali hari libur setelah shalat duhah berjamaah tepatnya pukul 06.30 WIB. Konsep dasar guru dalam mengajarakan mufrodat ialah mampu memetakan kemampuan siswa dalam memperoleh berbagai kosa kata bahasa Arab dan mengetahuai keberhasilan siswa setelah mempelajari mufrodat.

Upaya guru dalam mengajarkan mufrodat memiliki banyak problematika ketika pemilihan mufrodat sesuai dengan hasil wawancara bersama salah satu penyusun buku pedoman mufrodat untuk kelas satu Ust. Muhammad Nur Ahsan. Ia menyatakan dalam penyusunan buku pedoman terdapat tiga problematika diantaranya :

Pertama, menentukan klasifikasi kata bahasa Arab yang sesuai dengan kemampuan berbahasa siswa antar tingkatan kelas yang terdiri dari bermacammacam karakteristik.

Kedua, guru kurang bisa memprioritaskan antara kata benda atau kata kerja dalam mengajarkan mufrodat terutama kelas VII karena meraka baru mengenal dan mengikuti kegiatan pemberian mufrodat kebanyakan dari mereka merasa asing dengan pembelajaran ini.

Ketiga, guru tidak dapat mengetahui batas berbagai macam mufrodat yang harus diberikan kepada siswa sesuai kemampuan antar kelas.

13 Lexy J. Moleong, Metodologi Penelitian Kualitatif,(Bandung: PT. Remaja Rosda Karya, 2008) . 
Adapun langkah-langkah guru dalam memilih serta menentukan mufrodat untuk diberikan kepada para siswa terutama kelas VII dengan beberapa cara sebagai berikut :

1. Para guru pengampu bahasa berdiskusi untuk klasifikasi mufrodat bahasa Arab.

2. Mencari batas kemampuan siswa dengan memberi berbagai macam kosa kata sesuai kemampuan siswa antar kelas.

3. Menyusun mufrodat sesuai tema antar kelas, seperti kesepakatan guru bahasa unuk mufrodat kelas VII terbagi menjadi tujuh tema diantaranya tema kamar mandi, mushola, kamar, kebun, koperasi, kantor, dapur, dan kelas.

4. Menentukan intensitas pertemuan selama satu tahun terdiri dari dua semester.

5. Revisi dari berbagai kesalahan mufrodat atau disain cover buku yang kurang menarik sebelum terbit untuk digunakan dalam pembelajaran.

Pembelajaran mufrodat kelas VII MTs Fadlillah Sidoarjo menggunakan dua metode terdiri dari metode pertama al ilqo'iyah yaitu guru menyampaikan pengetahuan yang sesuai dengan pelajarannya sedangkan para siswa mendengarkan tanpa mengikutinya, metode kedua at tahawuriya yaitu metode percakapan antara guru dan siswa dengan berbagai pertanyaan dan jawaban yang sedang terjadi dalam pembelajaran sehingga siswa tertarik dan menjadikan mereka semangat dan berfikir cepat dalam memperoleh mufrodat baru. Dari kedua metode tersebut memudahkan guru untuk mengajar dan menyampaikan tiga kosa kata bahasa Arab dan menjadikan siswa lebih aktif mengikuti kegiatan pemberian mufrodat.

Hasil pemilihan mufrodat yang digunakan guru MTs. Fadllilllah pada kegiatan pemberian mufrodat berpedoman pada prespektif Rusydi Ahmad Thu'aimah, yaitu sebagai berikut: ${ }^{14}$

Prinsip pertama, التواتُر (Frequency), adalah penerapan mufrodat yang sering digunakan siswa dalam berkomunikasi dengan lawan bicara. Dalam buku pedoman ditemukan banyak mufrodat yang sudah menerapkan prinsip pertama dalam berkomunikasi setiap hari dan menjadi prioritas untuk diajarkan kepada siswa. Seperti tabel dibawah ini:

14 Rusydi Ahmad Thu'aimah, Ta'lim al-Arabiyyah fi Ghair al-Nathiqina biha; Manahijuhu wa Asalibuhu, (Rabath: Isisco, Cet I, 1989) h.195-196. 
El-Tsaqafah: Jurnal Jurusan PBA, Vol. 19, No.2, 2020

Tabel 1

Prinsip Frekuensi

\begin{tabular}{|c|c|c|}
\hline \multirow[t]{2}{*}{ TEMA } & \multicolumn{2}{|c|}{ KATA } \\
\hline & Kamar & حُجْرة \\
\hline \multirow[t]{3}{*}{ في الحثرة } & Lemari & خزَآنَة \\
\hline & Ranjang & سَرِيرِ \\
\hline & Kencing & بَالَ- يَبْولُ \\
\hline \multirow[t]{3}{*}{ في الحمّام } & Berak & 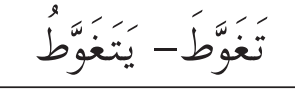 \\
\hline & WC & مرْحَاضُ \\
\hline & Membeli & اشْتَرَى - يَشْتَرى \\
\hline \multirow[t]{2}{*}{ في الخجرة } & Menjual & بَأعَ - يَبينُع \\
\hline & Lemari Es & 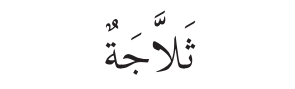 \\
\hline
\end{tabular}

Tabel diatas menunjukkan bahwa, pemilihan mufrodat pada buku pedoman yang digunakan oleh siswa kelas VII memiliki kesesuaian dengan penerapan siswa dalam berkomunikasi antar teman dalam keseharian mereka.

Prinsip kedua, التوازّع أو الـمدى (Range), merupakan mufrodat yang sudah diresmikan menjadi kata nasional negara Arab dan sering digunakan oleh orang Arab yang tertuliskan pada kamus, bukan mufrodat yang tercipta dari negara lain. Pada prinsip kedua ini tidak ditemukan mufrodat yang tidak sesuai dengan kamus.

Prinsip ketiga, الـمتاحية(Availability) atau ketersediaan. Sebuah kata yang dikuasai oleh siswa ketika ia mengutamakan mufrodat yang ia ketahui daripada tidak diketahui. Pada buku pedoman kelas VII ditemukan beberapa kata yang tidak sesuai dengan penguasaan siswa. Seperti tabel di bawah ini: 
Tabel 2

Prinsip Ketersediaan

\begin{tabular}{|c|c|c|c|}
\hline TEMA & \multicolumn{2}{|c|}{ KATA } & PEMBENARAN \\
\hline في الذبستان وفي & Cabang & شُعَبَةُ & فَرَع \\
\hline \multirow[t]{2}{*}{ في الثركة } & Uang & تَقْديُ & نُقُوْدود \\
\hline & Pensil & قَلُُْ الرَََّصَص & مرَسَ" \\
\hline \multirow[t]{2}{*}{ في الفصل } & Kotak Pensil & عُلَيَة الأَقْلَمَ & مقْلَمَةُ \\
\hline & Silet & مُوْسَى & شَفْرُة \\
\hline
\end{tabular}

Dari beberapa contoh kata diatas merupakan contoh tertulis. Penggunaan

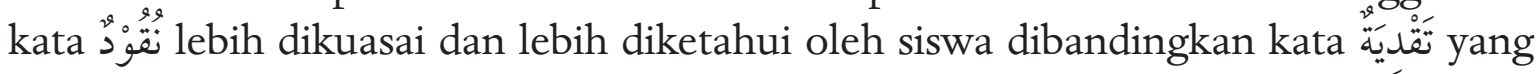
memiliki arti uang.

Prinsip keempat, الألفة (Familiar), merupakan kata yang sering didengarkan dan digunakan siswa dalam percakapan maupun tulisan, sehingga guru harus mengutamakan pemberian mufrodat yang familiar daripada kata yang jarang digunakan, meskipun memiliki kesamaan makna. Dalam pemilihan mufrodat dianjurkan guru memilih mufrodat yang lebih familiar dan memberikan persamaan kata agar siswa tertarik untuk berfikir kreatif dan lebih aktif dalam pembelajaran mufrodat bahasa Arab. Adapun beberapa kata yang tidak sesuai dengan artinya yang tertulis di buku pedoman pembelajaran mufrodat kelas tujuh sebagai berikut:

Tabel 3

Prinsip Familiar

\begin{tabular}{|c|c|c|c|}
\hline TEMA & \multicolumn{2}{|c|}{ KATA } & PEMBENARAN \\
\hline \multirow{2}{*}{ في الخجرة } & Mengembalikan & رَاجَعَ - يُرَاجعُع & رَدَّ - لَرَّدُ \\
\hline & Mencari & بَحَثَ - يَبْحَثُ & بَحَثَ - يَبْحَثُ عَنْ \\
\hline في الفصل & Seragam & لبَاس رَنْمِيُّ & 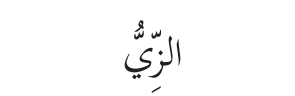 \\
\hline في الحمّمام & $\begin{array}{l}\text { Mandi Air Han- } \\
\text { gat }\end{array}$ & اسْتَحَمََّّ - يَسْتَحَمٌُ & Mandi \\
\hline
\end{tabular}


Dari kata-kata tersebut diatas merupakan contoh dari prinsip familiar yang terdapat di buku pedoman. Pemilihan kata اسنتَحَََّ - يَسْتَحِمُّ yang diberi makna mandi air hangat, merupakan makna kata yang tidak familiar pada siswa, mereka lebih mengenal dengan arti kata mandi. Begitu pula dengan kata لَبَاسٌ رَسْمِيٌ siswa lebih familiar dengan kata النّيُّ yang memiliki arti seragam.

Prinsip kelima, الشمول(Coverage) atau yang disebut dengan ketercakupan adalah kata yang memiliki pengertian dalam mencakup banyak hal yang perlu diprioritaskan dari pada kata yang sekedar digunakan dalam satu bidang saja. Pada prinsip ini, guru harus membedakan mufrodat yang akan diberikan berdasarkan kata yanglebih umum digunakan oleh siswa agar mudah diterima dan diterapkan dalam percapakan dan tulisan berbahasa Arab.

Tabel 4

Prinsip Ketercakupan

\begin{tabular}{|c|c|c|c|}
\hline TEMA & \multicolumn{2}{|c|}{ KATA } & PEMBENARAN \\
\hline في الشركة & Minyak Wangi & زَيْتُ عِطريْ & طِيْبُ \\
\hline \multirow{2}{*}{ في المطبخ } & Serbet & خرَفَّْ & منْدَيْلْ \\
\hline & Membedakan & خَرَقَق - يَخْرُقُق & فَرَّقَ - يُفَرَّقُ \\
\hline \multirow{3}{*}{ في الفصل } & Mengajar & عَلَمَ - يَعْلَُ & عَلَّمَ - يُعَلِّهُ \\
\hline & Spidol & مقْلمَة & معْلَمَة \\
\hline & Memandang & شَاهَدَ - يُشَاهدُ & Menyaksikan \\
\hline
\end{tabular}

Beberapa kata tersebut diatas merupakan contoh dari prinsip ketercakupan terlihat guru kurang dapat memprioritaskan kata yang umum sehingga susah untuk dimengerti siswa. Misal, kata شَاهَدَ - يُشَاهدل yang diartikan memandang kurang sesuai dengan arti pada umumnya yańg memiliki arti menyaksikan.

Prinsip keenam, الأهمية (Significance) bermakna kepentingan, merupakan kata yang perlu dan dianggap penting untuk diketahui oleh siswa harus diutamakan dari pada yang kurang atau tidak sedang dibutuhkan mereka. Melalui hasil wawancara dengan anggota penyusun buku pedoman untuk kelas tujuh mereka menyatakan bahwasanya untuk materi mufrodat kelas dasar mereka mementingkan agar siswa mengetahui tentang isim-isim yang ada dikalangan mereka dan menambahi dengan kata kerja agar mereka terbiasa dan menggunakannya dalam percakapan sehari-hari. Adapun materi kelas dasar meliputi mufrodat yang terdapat di kamar, mushollah, kamar mandi, kebun, kantin, kantor, dapur, dan kelas. Dengan demikian harapan 
para guru agar mereka hafal dan menggunakannya dalam bercakap-cakap berbahasa Arab dengan temannya.

Prinsip ketujuh, العروبة(Ke-Araban), yaitu mufrodat yang dipilih untuk diajarkan adalah kata-kata yang berasal dari negara Arab. Pada buku pengajaran mufrodat kelas VII yang digunakan oleh guru dalam mengajarkan di kelas ditemukan kata yang mengambil serapan dari bahasa lain yaitu seperti tabel dibawah ini:

Tabel 5

Prinsip Frekuensi

\begin{tabular}{|c|c|c|}
\hline TEMA & \multicolumn{2}{|c|}{ KATA } \\
\hline \multirow{2}{*}{ في الحمّمام } & Sabun & صَابُوْنْ \\
\hline & Shampoo & شَامنْبونْ \\
\hline \multirow{6}{*}{ في المطبخ } & Minuman Soda & مَاءُ الصُّودًَا \\
\hline & Manga & مَنْغَا \\
\hline & Kiwi & كيوي \\
\hline & Lemon & لَيمُوْنَ' \\
\hline & Papaya & بَابَاِيا \\
\hline & Nanas & اَنَانَاسُّ2 \\
\hline
\end{tabular}

Dari delapan kata tersebut diatas merupakan kata serapan dari bahasa asing yang telah disepakati dan digunakan oleh orang Arab dengan bukti ditemukannya kata-kata tersebut di dalam kamus.

\section{E. Penutup}

Mufrodat merupakan unsur dasar pembelajaran bahasa Arab yang perlu dikuasai siswa dalam belajar bahasa asing. Dengan demikian, diperlukan strategi pembelajaran mufrodat yang tepat. Banyak ditemukan problematika dalam pemilihan materi mufrodat khususnya di MTs. Fadlillah kelas VII Sidoarjo. Untuk mengatasi problematika yang dialami oleh guru dalam pemilihan mufrodat, penulis mengacu pada tujuh prinsip pemilihan mufrodat menurut Rusydi Ahmad Thu'aimah guna mempermudah guru dalam menentukan materi mufrodat.

Adapun hasil dari penelitian kali ini ditemukan adanya materi mufrodat berdasakan frequency, significance, dan prinsip ke-Araban sudah diterapkan dalam pembuatan materi mufrodat yang akan diajarkan kepada anak kelas VII MTs. Fadlillah sudah sesuai dengan kemampuan para siswa. Pertama, guru mampu memilih bahasa yang lebih mudah dan sering digunakan dalam keseharian mereka. Kedua, mengetahui prioritas kata sesuai dengan kemapuan siswa. Ketiga, terdapat delapan 
kata yang merupakan kata serapan dari bahasa asing yang mana telah menjadi bahasa resmi orang Arab. Sedangkan menurut beberapa prinsip lain seperti prinsip Range, Availability (ketersediaan), seringnya penggunaan (Familiar), ketercakupan (Coverage), memiliki kata-kata yang tidak sesuai dengan prespektif Rusydi Ahmad Thu'aimah.

\section{Daftar Pustaka}

Albantani, Azkia Muharom (2014) "Mustawiyaat Talum wa Ta’liimil Lughah Al-Arobiyah 'Inda Rusydi Ahmad Thu'aimah”, Arabiyât Jurnal Pendidikan Bahasa Arab dan Kebahasaanaraban, vol. I, No. 1, Juni.

Al-Khuuli, Muhammad Ali. (2010). Strategi Pembelajaran Bahasa Arab, Yogyakarta: Basan Publishing.

Astuti, Widi, "Berbagai Strategi Pembelajaran Kosa Kata Bahasa Arab”, Jurnal Komunikasi dan Pendidikan Islam, Vol.5, No.2, Desember 2016.

Fajriah, Zahrotun, "Peningkatan Penguasaan Kosakata Bahasa Arab (Mufrodat) Melalui Penggunaan Media Kartu Kata Bergambar”, Jurnal Pendidikan Usia Dini, Vol. 9, Edisi 1, April 2015.

Haviz, M., "Research and Development; Penelitian Di Bidang Kependidikan yang Inovatif, Produktif, dan Bermakna, Jurnal Ta'dib, Vol. 16, No. 1, Juni 2013.

Kustiawan, Moh. Mansyur. (2002). Dalil al-Katib Wa al-Mutarajim, Jakarta: PT. Moyo Segoro Agung.

Moleong, Lexy J. (2008). Metodologi Penelitian Kualitatif, Bandung: PT. Remaja Rosda Karya.

Mu’at, "Strategi Pembelajaran Kosakata (Mufrodat) Bahasa Arab, Jurnal Al Ta'dib, Vol.3, No. 1, Juli 2013.

Nafis, Hafni Bik, dkk. t.t Qawaid al-Lughat al-Arabiyyah, Semarang: Maktabah al-Alawiyah.

Sugiyono, (2014). Metode Penelitian Kuantitatif Kualitatif dan RఠD, Bandung: Alfabeta.

Thiagarajan, Shivasailam, dkk, (1974). Instructional Development for Training Teachers of Exceptional Children, Washinton DC: National Center for Improvement System.

Thu'aimah, Rusydi Ahmad. (1989). Ta'lim Al-'Arabiyyah fi Ghair al-Nathiqina biha; Manahijuhu wa Asalibuhu, Rabath: Isisco. 